\title{
CRIANÇAS MIGRANTES: FOCO SERVIÇAL DA VENERÁVEL MADRE ASSUNTA
}

Ir. Erta Lemos, msCs*

Madre Assunta Marchetti, co-fundadora das Irmãs Missionárias de São Carlos Borremeo - Scalabrinianas, desde sua mais tenra infância, veio trabalhando na formação de sua personalidade com dedicação e fidelidade admiráveis. Muito cedo Assunta recebeu a graça da fé com a certeza de que Jesus era seu amigo e a ajudaria em tudo o que necessitasse. Esta sempre foi a fonte de onde tirava todas as graças que necessitava para seguir adiante com bom humor em todas as tarefas que lhe eram solicitadas.

Assim sendo, com a prática fiel da religião, com a obediência filial a toda prova, com seu bom humor e necessidade de ajudar os outros foi crescendo em idade e sabedoria (LC 2,52) diante dos homens e diante de Deus. Nada Ihe era difícil! Ou melhor, tudo em suas mãos se tornava possível: ajudar nos serviços da casa, no cuidado dos irmãos menores, substituir o pai e o irmão no moinho, dar catequese para os irmãos e crianças da vizinhança, além da oração e missa diárias. Durante os primeiros vinte e quatro anos de sua existência vividos na Itália, precisamente em Lombrici e Camaiore, seu caráter de mulher forte, bondosa, atenta e plenamente aberta à novidade de Deus foi tomando forma definitiva de uma mulher de Deus, feita serviço aos outros.

Naquele tempo, seu irmão, Pe. José Marchetti, scalabriniano, falou-lhe das inúmeras crianças migrantes órfãs e abandonadas em São Paulo que necessitavam de alguém para cuidar delas com amor e carinho, protegê-las e educá-las cristãmente ${ }^{1}$. Depois de perscrutar as profundezas do amor de Deus diante do Sagrado Coração de Jesus entendeu que o amor não tem limites nem fronteiras. Entendeu que servir a Deus como religiosa carmelita

\footnotetext{
Irmã missionária de São Carlos Borromeo, Scalabriniana. São Paulo/Brasil.

1 CONGREGAÇÃO das Irmãs Missionárias de São Carlos Borromeo, Brevi Cenni, p. 2.
} 
ou missionária era, para ela, a mesma coisa, por isso pode dizer seu sim definitivo e irrevogável. Assunta experimenta a grande liberdade dos filhos de Deus aceitando ser contemplativa na ação! Parte feliz para o Brasil com suas companheiras para nunca mais voltar a ver sua terra querida.

\section{Assunta Mãe}

Até aos vinte e quatro anos, sua vida foi um ensaio para se tornar uma mulher fecunda, naturalmente mãe, toda atenção atenta! Ninguém com necessidade de ajuda escapava ao seu olhar sempre atento. Seu coração vivia fora dela, nos outros, nos necessitados, abandonados, carentes. Sim, primeiro as crianças, depois os adolescentes sem excluir os mais idosos.

Como toda boa mãe, primeiro cuida do corpo, das feridas, da fome e da sede. Depois se desdobra em carinhos e atenções de toda sorte para dar um pouco de paz e de alegria aos pequenos. Acompanha-os nas brincadeiras, nos estudos e até mesmo durante o sono. Incansável? Sim. Incansável! Ela não foi mãe biológica, mas foi mãe espiritual de uma multidão de crianças, jovens e adolescentes. Bem como cultivava um amor de mãe para com as Irmãs de sua Congregação. Ela sempre a última a deitar e a primeira a se levantar. Não faz assim a mãe que é mãe? Tudo o que é melhor é para o outro, pois sua felicidade está na felicidade do outro!

Em tempos difíceis ela se desdobrava para conseguir meios de sustentação da instituição organizando grupos de oração, grupos de arrecadação de doações e grupos de trabalho voluntário a fim de proteger todos os pequenos que estavam sob seus cuidados: crianças, adolescentes e jovens. Todos migrantes. Amiúde havia até mais de 200 órfãos no Orfanato do Ipiranga e de Vila Prudente. Ela devia cuidar deles para que, no futuro, fossem bons e preparados cidadãos. Trabalhava para conservar-lhes a memória da pátria materna através da conservação da religião e da língua mãe. Ela, 'migrante com os migrantes', alimentava o desejo do retorno à sua terra natal, mas comprometeu-se com vontade amorosa para ajudar outros a serem homens e mulheres de bem e assim a missão fosse completa ${ }^{2}$.

\section{Assunta Mestra}

Os orientais nos ensinam que,

a Mestra na arte da vida faz pouca distinção entre o seu trabalho e o seu lazer, entre a sua mente e o seu corpo, entre a sua educação e a sua recreação, entre o seu amor e a sua religião. Ela dificilmente sabe distinguir um corpo do outro.

2 BONDI, Laura. Alguns Escritos Inéditos para evocar e aprofundar a figura de Padre José Marchetti, p. 26. 
Ela simplesmente persegue sua visão de excelência em tudo que faz, deixando para os outros a decisão de saber se está trabalhando ou se divertindo. Ela acha que está sempre fazendo as duas coisas simultaneamente ${ }^{3}$.

Este ensinamento combina perfeitamente com o perfil de Madre Assunta, mulher sem divisão, inteira em tudo e por tudo. Só este jeito de ser fazia e faz dela uma grande educadora. Todos aprendiam com ela. Se não as ciências exatas, as ciências de uma vida ativa, fecunda, alegre e esperançosa. É admirável sua capacidade de acolher as várias inteligências ${ }^{4}$ e proporcionar-lhes condições de desenvolvimento naquilo em que eram melhores! Que respeito às diferenças individuais! Quando chamava a atenção, fazia-o com tanto amor que o faltoso jamais se ofendia, ao contrário aumentava nele o desejo de emendar-se e fazer melhor da próxima vez. Tinha interiorizado o principio ditado pela vida e palavras do irmão: "Os direitos de todas as crianças podem e devem ser atendidos. O silêncio, a omissão já roubaram a vida de muitas crianças. Previna! Alerte! Denuncie para que não seja tarde demais" (Pe. J. Marchetti, 1896). Que sabedoria nos momentos difíceis e dolorosos! Sua paz interior contagiava... Todos se sentiam seguros perto dela! Sua atitude interior era a mesma quando diante dos superiores como diante do mais pequeno entre seus educandos.

De cada jovem sabia pedir o melhor e obtinha a resposta desejada. Era atenta ao desenvolvimento integral de cada um de seus pupilos. Da cura do corpo à cura da alma. Tratava cada um como um projeto a ser desenvolvido, jamais exigiu de um jovem algo que só o adulto poderia fazer. Ensinava com a vida, com a presença, com amor, com alegria e muita sabedoria. Da horta ao pomar, do quarto à capela, da cozinha ao refeitório, da sala de aula à sala de estudos, do recreio às aulas especiais de corte e costura, sapataria, carpintaria, alfaiataria, padaria, música e canto, e tipografia.

Como seu irmão Marchetti, madre Assunta acreditava que as crianças deviam permanecer na Instituição até a maioridade, com o intuito de preservar-lhes a dignidade de filhos de Deus e incrementar nelas a formação em sentido global, certa de estar colaborando para a construção de cidadãos corresponsáveis pelo bem comum, pois tinha a convicção que "dentre as crianças sairão artistas, professores, médicos, missionários" como dizia padre José Marchetti (1896). Assunta, antecipou com sua doação heroica o que diz o Estatuto da Criança e Adolescente: "É dever da família, da comunidade, da sociedade em geral, e do poder público assegurar, com absoluta prioridade, a efetivação dos direitos referentes à vida, à saúde, à alimentação, à educação,

TEXTO Budista.

4 Cf. GARDNER, Howard. Teoria das inteligências múltiplas. 
ao esporte, ao lazer, à profissionalização, à cultura, à dignidade, ao respeito, à liberdade e à convivência familiar e comunitária" (ECA, art. 4). Fez sua parte com amor e responsabilidade, engajando outras no serviço aos pequenos.

\section{Assunta na busca da santidade}

De acordo com os vários testemunhos, Madre Assunta foi heróica na vivência de todas as virtudes tanto as menores (sorriso) quanto as maiores (humildade). Porém o que mais chama a atenção é seu contínuo êxodo de si mesma, da própria vontade, dos próprios prazeres, das próprias idéias! Sabia interagir com os pequenos, com os adolescentes e com jovens de uma maneira única. Como se entendiam! Não era diferente com os adultos e com as coirmãs. Era o jeito dela de praticar o mandato do Senhor que disse "sede perfeitos como vosso Pai Celeste é perfeito" (Mt 5,48). Ela amava a todos sem distinção. Fazia tudo bem feito. E isso fez e faz toda a diferença!

Durante os 52 anos de missão no Brasil entre os migrantes mais necessitados tanto em São Paulo (800.000), quanto no Rio Grande do Sul $(250.000)^{5}$, ela fez de tudo: lavou, passou, cozinhou, cuidou, orientou, ensinou, dirigiu, rezou, sofreu, ofereceu, suportou, resistiu, superou, governou, obedeceu, se alegrou, viveu intensamente todos os momentos de sua existência e faleceu na paz do Senhor se oferecendo como vítima de amor pelos seus pequenos e pela sua querida congregação. E, na pessoa de outras mulheres consagradas a obra de atendimento às crianças e adolescentes continua, sobretudo na Casa Madre Assunta de Vila Prudente, São Paulo.

Em 25 de outubro de 2014 Madre Assunta Marchetti será beatificada e continuará, com novo titulo a interceder por todas as crianças, jovens e adolescentes que vivem como migrantes, fora de sua pátria, buscando melhores condições de vida, pois foi para a liberdade que Cristo nos libertou!

\section{Referências Bibliográficas}

BONDI, Laura, mscs. Madre Assunta Marchetti, uma Vita Missionaria. Brasília: CSEM, 2011. . Alguns Escritos Inéditos para Evocar e Aprofundar a Figura de Padre José Marchetti, cs. São Paulo: Edições Loyola, 1993.

CONGREGAÇÃO das Irmãs Missionárias de São Carlos Borromeo. Brevi Cenni. Roma, 1991. GARDNER, Howard. Teoria das inteligências múltiplas. Disponível em: <http://www. suapesquisa.com/educacaoesportes/inteligencias_multiplas.htm>.

SIGNOR, Lice Maria, mscs. João Batista Scalabrini e a Migração Italiana, um projeto sóciopastoral. Porto Alegre: Pallotti, 1986.

TEXTO Budista. Disponível em: <http://pensador.uol.com.br/mestre/>.

\footnotetext{
5 SIGNOR, Lice Maria. João Batista Scalabrini e a Migração Italiana,um projeto sócio-pastoral, p. 95.
} 